\title{
Application of Fuzzy TOPSIS for Evaluation of Green Supply Chain Management Practices (Case study: Zanjan Sepehr Khodro; Iran)
}

\author{
Ahmad Hashemi $^{1 *}$, Rasoul Esrafilian ${ }^{2}$, Sima Hadavand $^{3}$, Mohammad Zeraatkar ${ }^{1}$ \\ ${ }^{1} \mathrm{PhD}$ student of industrial engineering, department of Industrial Engineering, Faculty of Internatinal Pardis, \\ Kharazmi University, Tehran, Iran. \\ ${ }^{2}$ Master graduated of industrial engineering, department of Industrial Engineering, Faculty of Mechanical \\ Engineering, University Technology Malaysia, 81310 UTM Johor Bahru, Johor, Malaysia \\ ${ }^{3}$ Master student of industrial engineering, department of industrial engineering, Faculty of industrial engineering \\ and management systems, Amirkabir university of technology, Tehran, Iran.
}

\begin{abstract}
Despite the immense number of papers on green supply chain practices, proposing the most important practices of green supply chain management (GSCM) is less investigated. Consequently, this study aims to provide an incorporated process to find and rank the most important practices of green supply chain management (GSCM) for an empirical case study of Zanjan Sepehr Khodro (SKZ). Firstly, a systematic literature review is conducted to find the major practices of green supply chain management (GSCM). Next, three practices with their sub-criteria have been selected based on their frequency of application. These practices are then categorized based on the major perspectives of green supply chain management (GSCM). Finally, A Fuzzy TOPSIS methodology is applied to rank the green supply chain management (GSCM) practices and find their importance level in corresponding company. According to the results, the final rankings of practices are green recycling, green purchasing and green warehousing respectively.
\end{abstract}

Keywords: Green supply chain management; Green practices; Fuzzy logic; Fuzzy TOPSIS

\section{Introduction}

Today's competitive business environment has imposed many firms to concentrate on supply chain management to earn a competitive advantage. During recent years, green supply chain in the whole supply chain study has become a key strategic topic and thoughtfulness. Regarding the raising global understanding of environmental protection and the corresponding growing regulations, green design, green production, green purchasing, green warehousing, green transportation and the green recycling have become important issues for firms to acquire sustainability [1]. Green supply chain management is a proactive approach to enhance products environmental performance and take into account the environmental regulations requirements as well [2]. Environmentally sustainable issues are getting interested among the companies which are improving their practices in the supply chain management increasingly. Despite the fact environmental regulations and legislation are forcing firms to consider these issues, still, green issues are new and there is a great need to be studied continuously [3].

The main objective of this paper is to propose comprehensive and important practices to evaluate the GSCM practitioners using fuzzy TOPSIS. Meanwhile, according to the following literature, there is no study in the area of GSCM framework applying TOPSIS in fuzzy environment. Hence, this is the first research trying to utilize this technique to inspect green practices. The contribution of this paper is briefed as follow: the study has submitted more important green practices based on literature and an expert team for motorcycle manufacturing companies. The most important practices have been highlighted by the applied technique named TOPSIS fuzzy.

The rest of this paper is founded as follows. The next section is an overview of GSCM literature. During this section, the study will attempt to draw 20 sub-criteria which are more important indicators and categorize them into 6 categories. Each of categories cover most important practices named green practices. In Section 3, fuzzy sets, fuzzy numbers and the applied methodology are explained. Research methodology and the practical case study are elaborately explained at next section. In Section 5, results and discussions are submitted Finally, in Section 6, conclusions and outlines for future studies are clarified. 


\section{Literature}

In the current competitive business world, environmental concerns have been taken into account based on green and sustainable development. Development of environmental protection, has forced organizations to consider environmental practices to reinforce the green reputation of their own companies, alongside by practical commitment to protection of environment [4]. Applying more standards, agreement and responsibilities on activities like raw material extraction and overflowing waste sites to prevent environmental deterioration and pollution, help companies to access the mentioned reputation [5]. GSCM is an absolutely essential issue that can be considered as framework to the philosophy of management science to integrate all supply chain parts which is taken into account as a humane and advanced practice for organizations [6] and [7]. It earns economic benefits to the manufacturers as well [8]. In addition, in spite of GSCM popularity in the industrial countries, it sounds still there are countries which have not taken into account GSCM practically [9]. GSCM is prior to other philosophies in new markets, because it has more profits comparing with the rest of management philosophies [10]. Selecting the best practices of GSCM to construct its framework, has been one of considerable problem which tools such as multi criteria decision making (MCDM) has the potential ability to solve it [11], [12], [13], [14] and [15]. Thus, we need to apply MCDM tools to overcome this problem. Meanwhile, to have aware consumers with consciousness seek encountering environmental issues need rigorous environmental legislations and regulations which impose manufacturers to accommodate their organizational practices with environmental concerns [16]. There is lack of a general framework to depict practical roadmap of organizations which highlights the weaknesses of studies in this area, however, there are strengths regarding environmental concerns that causes competitive advantage and should not be disregarded [17]. And that's why like HP, Sony, IBM, Motorola, Panasonic, Dell, Fujitsu and Toshiba, are struggling to adopt GSCM, applying its instruction practically and claiming that GSCM has a proactive advantages for their operational processes in terms of environmental protection [18], [19], [20], [21] and [22]. The following researches are some of studies related with Green Supply Chain Management (GSCM).

Reference [17] created a rating system including the main practices of design for the environment, life cycle analysis, total quality environmental management (TQEM), green supply chain and ISO 14000 environmental management system (EMS) requirements. [18] Proposed performance indicators with key evaluating criteria of top and middle management support, firm's mission, department goals, training for personnel to buy environmentally friendly input, and evaluation of purchasing management on German purchasing. [19] Investigated a measurement model with key measures of hazardous materials, investment recovery, product design, and supply chain relationships. [23] and [24] implemented a performance framework with key practice of reverse logistics. Eco-design, reverse logistics were concentrated by [25] as well. Environmental management system, suppliers process, product (recycling, packaging and production spill), transportation (return loads, choice of transportation, supplier's geographical location and optimizing loads) were key indicators of model implemented by [26]. [27] Focused on Green purchasing (GP) and supplier environmental collaboration in his measurement. KPIs of ISO 14000 certified, Ozone depleting substances, recyclable content, volatile organic compounds content, on Environmental Protection Agency 17 hazardous material list, remanufacturing/reuse activity, returnable or reduced packaging, take back or reverse logistics, participation in voluntary Environmental Protection Agency (EPA) programs, public disclosure of environmental record are measures investigated by [28]. Criteria of Internal environmental management (IEM), external green supply chain management, investment recovery (IR), and eco-design, environmental performance and economic performance are the main indicators of the next research by [29]. Another study in this area belongs to [30] working on Green purchasing, green manufacturing, green packaging, and reverse logistics. Green purchasing, supplier environmental collaboration have been investigated by [31] as well. Re-use, remanufacturing, and recycling which are embedded in green design, green procurement practices, environmental management, environmentally friendly packaging, transportation and product end-of-life were the most important key practices in point of [32] view. [33] and [34] claim that Re-use and recycling, life cycle of products and services are important measures. [35] and [36] believe environmental collaboration with suppliers and customers is a key indicator to be taken into account. Product design, material purchasing, manufacturing processes, final product delivery, disposal, and the product end-of-life management are considered prominent practices by [37] and [38].

References [39] and [40] studied on measures of eco design, environmental certification, development of clean technologies, the use of environmentally friendly materials, return and reuse of packaging, the use of life cycle assessment (LCA) or waste management and reduction in environmental emissions in their model. Ecodesign, environmental performance, positive economic performance, ISO 14000 certificates, commitment of green supply chain management from senior and mid-level managers were researched by [25]. Environmental product design, reduction of material and energy usage, environmental management procedures for internal use, use of advanced prevention and safety systems at work, filters and controls for emissions and discharges are key practices of model presented by [26]. Total product life cycle cost, green image, pollution control, environment management, green product, green packaging, and green competencies are constructs of framework which are 
re-investigated by [27]. Key indicators of external (Legislation, competitive, supply chain, societal) drivers, green materials coding, Green process management, Internal environmental management and cooperation with customers, green marketing, green market share, green supply chain management pressure (market regulatory competition), pollution treatment cost, ozone depleting chemicals, the degree of green collaboration with suppliers, collaboration between product designers and suppliers to reduce and eliminate product environmental impacts, green supply chain outcomes (environmental, economic, operational, intangible), recycling products processing ability, shipping documentation and reliability of delivery have been applied by [28], [29], [30], [31], [32], [33], [34], [35], [36], [37], [38], [39], [40], [41] and [42] respectively. As well as, the reference [43] invested on practices of pollution control initiatives, use of environment friendly technology, partnership with green organizations and suppliers, environmental certification, positive economic performance, decrease of cost for materials purchasing, decrease of cost for energy consumption, decrease of fee for waste treatment, decrease of fee for waste discharge, negative economic increase of investment, increase of operational cost, materials, operational performance scrap/ waste reduction, quality improvement, delivery improvement and capacity utilization improvement in a comprehensive research. Among all practices that reference [44] investigated, the following practice are more important to grasp GSCM which are; to redefine operation and production processes to ensure internal efficiency that can help to implement GSCM, redesigning and improving the product or service in environmental directives, reduction of hazardous waste, emission, etc., less consumption of e.g. water, electricity, gas and petrol, to install EMS and ISO 14000 series, providing environmental awareness seminars and training for stakeholders, advanced green production technology, to recycle, reuse and remanufacture material, use of cleaner technology such as energy, water and waste, sending in-house auditor to appraise environmental performance of supplier, process design and innovation and enhances R\&D functions. GSCM researcher [45] emphasized on practices of providing consumers with information on environmentally friendly products and/or production methods, change to more environment-friendly transportation and taking back packaging between strategic KPIs, while [46] found staff environmental training more important practice than the rest. Recently, reference, [47] distinguished practices of commitment of senior management to GSCM, interfunctional cooperation for environmental improvement, compliance with legal environmental requirements and auditing programs, sale of excess stock or materials, sale of scrap and used materials, sale of used equipment (after buying new equipment).

To categorize above criteria, study refers to the literature. Practices of eco-design also called as design for the environment and green design (C1), design of products for reuse, recycle, recovery of materials, component parts (C2) and design of products to avoid or reduce the use of hazardous products (C3) are considered as sub criteria of green design by [47], [48] and [49] respectively. Eco-design also called as design for the environment and green design, includes activities that aim to minimize environmental impacts of products during their entire life cycle. Green purchasing includes activities that aim to make sure that the purchased items have desirable environmental attributes such as reusability, recyclability, and the absence of hazardous materials. The category of green purchasing includes sub criteria of buying environment-friendly raw materials (C4), choice of suppliers by considering the environmental criteria (C5), supplier environmental management system (EMSs) (C6) and environmental audit of suppliers' internal management (C7) applied by [50], [51], [52] and [53] respectively. As well as, re-manufacturing and lean production (C8), cleaner production (C9), to decrease scrap (C10) and improved capacity utilization (C11) are sub criteria utilized to construct indicators of GSCM in category of green production by researchers [54], [55], [56] and [57] respectively. Green production (C3) or manufacturing aims for continuous improvements of industrial processes and products to reduce or prevent pollution to air, water and land which results in the possibility of minimizing risks to humans and other species. Furthermore, green warehousing is taken into account by GSCM researchers of [58], [59], [60] and [61] which cover sub criteria of sale of excess inventories/ materials (C13), sale of scrap and used materials (C14), sale of excess capital equipment (C15) and environmentally friendly packaging (C16). In addition, among the green initiatives, green transportation received the least importance and just few studies have been executed in this category. In this study, the mentioned category is arranged by sub criteria of environmentally friendly transportation (C17) and environment-friendly distribution (C18) researched by [62] and [63] correspondingly. Finally, green recycling or reverse logistics include activities that aim at taking back products or materials for the purposes of reuse or recycling, remanufacture, repair, refurbishing, or safe disposal of the products and materials. This category includes two criteria of use of alternative sources of energy (C19) and Use of waste of other companies (C20) studied by [64] and [65] respectively.

In the current study, according to the literature, multiplicity of practices and their applications we have applied green practices of green purchasing, green warehousing and green recycling. Each of these practices covers some sub-criteria which are mentioned in literature. 


\section{Fuzzy sets and fuzzy numbers}

In many cases, exact data is not adequate to model realistic situations and circumstances in our life, because human precedence is often subjective and uncertain and cannot be assessed with exact numerical values. Fuzzy set theory was developed by [66] to determine the complexity of human perception in order to project data by preparing mathematical effective nesses to solve ambiguity and uncertainties to enable partial set membership than the unstable set membership. Reference [66] were the first researchers to review the decision-making problem applying fuzzy sets, and presented the fuzzy multi criteria decision-making methodology for first time [67]. The study has applied triangular fuzzy numbers to estimate the preferences for its simplexes that let DMs to use it. A triangular fuzzy number is specified by $(a, b, c)$ where $a \leq b \leq c$. The parameters $a, b$ and $c$ are the smallest possible, the most promising and the largest possible value respectively. In case of supposing $\mathrm{X}$ a group of items, known as the universe, and its elements are symbolized by $\mathrm{x}$. in addition a fuzzy subset of $\mathrm{X}$ denoted by is represented by a membership function of $f_{A}(x)$ and is associated with each element $\mathrm{x}$ in $\mathrm{A}$ and a number between 0 and 1. A fuzzy set is defined by its own membership function as follow and is displayed in Fig. 1.

$$
f_{A}(x)= \begin{cases}\frac{x-a}{b-a} & x<a, x<c, a \leq x \leq b \\ \frac{c-x}{c-b} & b \leq x \leq c\end{cases}
$$

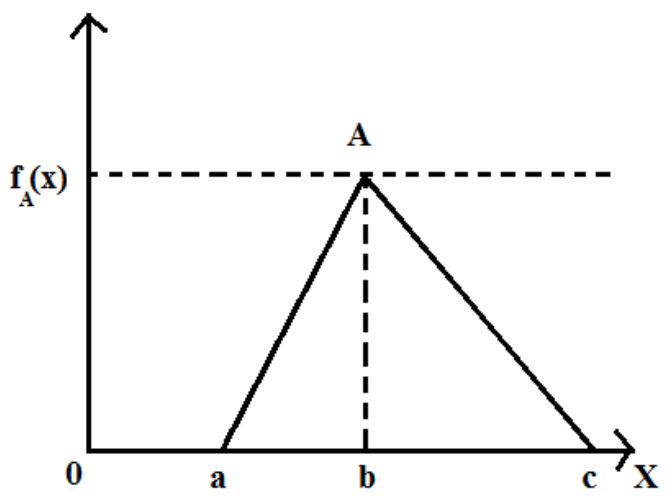

Fig 1. Membership function of triangular fuzzy number A

At the following calculations, the study introduces some basic definitions of fuzzy concepts that are applied in the proposed fuzzy TOPSIS method in previous studies such as [67] and [68].

Let $\mathrm{A}=(\mathrm{a}, \mathrm{b}, \mathrm{c})$ and $\mathrm{B}=(\mathrm{a} 1, \mathrm{~b} 1, \mathrm{c} 1)$ be two triangular fuzzy numbers. Then the basic operations of triangular fuzzy numbers are defined as follows:

$$
\begin{aligned}
& A(+) B=(a, b, c)(+)\left(a_{1}, b_{1}, c_{1}\right)=\left(a+a_{1}, b+b_{1}, c+c_{1}\right) \\
& A(-) B=(a, b, c)(-)\left(a_{1}, b_{1}, c_{1}\right)=\left(a-a_{1}, b-b_{1}, c-c_{1}\right) \\
& K A=(k a, k b, k c) \\
& (A)^{-1}=\left(\frac{1}{a}, \frac{1}{b}, \frac{1}{c}\right)
\end{aligned}
$$

The distance between fuzzy numbers A, B is calculated as:

$$
d(A, B)=\sqrt{\frac{1}{3}\left[\left(a-a_{1}\right)^{2}+\left(b-b_{1}\right)^{2}+\left(c-c_{1}\right)^{2}\right.}
$$


Assume that a decision group has $\mathrm{K}$ decision makers, and the fuzzy rating of each decision maker $\mathrm{D}_{k}(\mathrm{k}=1,2$,

..,K) can be represented as a positive triangular fuzzy number $R_{k} \quad(\mathrm{k}=1,2, \ldots, \mathrm{K})$ with membership function $F_{R_{k}}(x)$. Then the aggregated fuzzy rating can be defined as:

$$
R=(a, b, c) \quad k=1,2,3, \ldots ., \mathrm{K}
$$

$$
\text { Where } a=\min _{k}\left\{a_{k}\right\}, b=1 / k \sum_{k=1}^{k} b_{k} \text {, and } c=\max _{k}\left\{c_{k}\right\} \text {. }
$$

\section{Methodology}

TOPSIS is a classical method for solving MCDM problems. It was developed by [69]. The origin of TOPSIS is derived from the concept that the selected alternative needs to have the shortest distance from the positive ideal solution (PIS) and the farthest from the negative ideal solution (NIS) for solving a MCDM problem [64]. TOPSIS has a simple calculation procedure, systematic process and a reasonable logic that submit the rationality of human choice. It covers a wide range of practices (performance criteria) and causes transparent trade-offs between criteria meaning any changes in one criterion can be compensated by other criteria. Pair-wise comparisons, required by technique such as AHP, are avoided [61], [62], [60] and [55]. The TOPSIS method takes into account distances from the PIS and the NIS simultaneously by applying the definition of "relative closeness to ideal solution". Finally, the closest ideal solution to the PIS and farthest to the NIS is obtained. The TOPSIS solution method covers the following steps [65]:

Step 1: The normalized fuzzy-decision matrix can be represented as:

$$
R=\left[\mathrm{r}_{i j}\right]_{m . n}
$$

Where $\mathrm{B}$ and $\mathrm{C}$ are the sets of benefit and cost criteria, respectively, and

$$
\begin{aligned}
& r_{i j}=\left(\frac{a_{i j}}{c_{j}}, \frac{b_{i j}}{c_{j}}, \frac{c_{i j}}{c_{j}}\right) \\
& {c^{+}}_{j}=\max _{i} \quad c_{i j}, j \in B \\
& r_{i j}=\left(\frac{a_{j}^{-}}{c_{i j}}, \frac{a_{j}}{b_{i j}}, \frac{a_{j}^{-}}{c_{j} a_{i j}}\right) \\
& a_{j}^{-}=\min _{i} \quad a_{i j}, j \in \mathrm{C}
\end{aligned}
$$

Step 2: Weighted normalized decision matrix $v_{i j}$ is calculated by multiplying normalized matrix with the weights of the criteria:

$$
V=\left[v_{i j}\right] m \quad i=1,2, \ldots ., m ; j=1,2, \ldots . ., n
$$

$$
\text { Where } v_{i j}=r_{i j} \quad \cdot w_{j} \text { and } w_{j} \text { is the weight of the jth attribute or criterion. }
$$

Step 3: The positive-ideal solution (PIS, $\mathrm{A}^{*}$ ) and negative-ideal solution (NIS, $\mathrm{A}^{-}$) can be calculated as

$$
v_{i j}=\frac{-a_{i j}^{2}-a_{i j} \cdot b_{i j}+b_{i j} \cdot c_{i j}+c_{i j}^{2}}{3\left(c_{i j}-a_{i j}\right)}
$$




$$
\begin{aligned}
& A^{*}=\left(v_{1}^{*}, v_{2}^{*}, \ldots, v_{n}^{*}\right) \\
& A^{-}=\left(v_{1}^{-}, v_{2}^{-}, \ldots, v_{n}^{-}\right)
\end{aligned}
$$

$$
\text { Where } v_{j}^{*}=\max _{i}\left\{v_{i j a}\right\} \text { and } v_{j}^{-}=\min _{i}\left\{v_{i j a}\right\}, \mathrm{i}=1,2, \ldots, \mathrm{m}, \mathrm{j}=1,2, \ldots, \mathrm{n} \text {. }
$$

Step 4: The distance of each alternative from PIS and NIS is calculated as:

$$
\begin{aligned}
& d_{i}^{*}=\sum_{j=1}^{n} d_{v}\left(v_{i j}, v_{j}^{*}\right), \quad i=1,2, \ldots . ., m \\
& d_{i}^{-}=\sum_{j=1}^{n} d_{v}\left(v_{i j}, \overline{v_{j}}\right), \quad i=1,2, \ldots \ldots, m
\end{aligned}
$$

Step 5: The closeness coefficient (CCi) of each alternative is calculated as:

$$
O C_{i}=\frac{d_{i}^{-}}{d_{i}^{-}+d_{i}^{*}} \quad i=1,2, \ldots . ., m
$$

Step 6: At the end of the analysis, the ranking of alternatives is determined by comparing CCi values. Alternative $\mathrm{Ai}$ is closer to the FPIS (A*) and farther from FNIS (A-) as CC1 approaches to 1 . The ranking order of all alternatives is determined according to the descending order of $\mathrm{CC} 1$.

\section{A fuzzy multi criteria approach for green practices selection (calculations and discussions)}

This study presents a practical example (Zanjan Sepehr Khodro) for application of fuzzy TOPSIS methodology to select the best green practices based on environmental criteria in a motorcycle manufacturing company. In order to access the mentioned goal, the aim of this study is to propose the fuzzy TOPSIS model for green practices selection and evaluation and to recognize the most important practices for our case study (Zanjan Sepehr Khodro) applying practical example.

Manufacturing operations have a main impact on environmental pollution during different stages of product life cycle, from resource extraction to manufacturing, use, reuse, recycling and disposal. Motorcycle manufacturing companies need to start to develop green practices over the manufacturing process to achieve ecological efficiency. This improvement is essential to access competitive advantages in the company's environmental performance. The proposed approach includes two steps of selection of evaluation criteria and the evaluation and selection of best practices using proposed criteria.

The first step involves the selection of criteria for evaluating the environmental effects of green practices. A comprehensive literature associated with GSCM was applied to select the needed practices. The needed criteria to be considered as base for our study have already been discussed and taken from internal customers (personnel) as follow. These criteria have been taken applying a simple questionnaire. According to the expectations of Sepehr Khodro' personnel, the study have selected 10 criteria to grasp which one of green practices is more important to satisfy the following expectations (criteria). It is worthy to say that Sepehr Khodro company includes different divisions as follow:

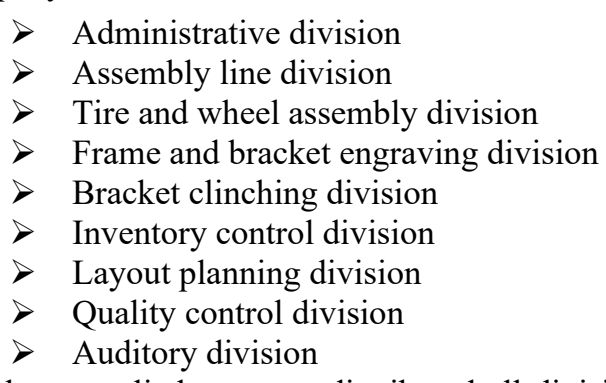

The study have applied a survey distributed all divisions to figure out which criteria are more important for the company and finally has accessed the following Table1. 
Table1. Criteria for selecting and evaluating green suppliers

\begin{tabular}{|c|c|c|}
\hline Internal customers' expectations & Different divisions & Cost/benefit criteria \\
\hline Presence of hazardous materials & expectations of all divisions & Cost \\
\hline Use of environmentally friendly technology & $\begin{array}{l}\text { expectations of assembly line and frame and } \\
\text { bracket engraving division }\end{array}$ & Benefit \\
\hline Lack of environmentally friendly materials & $\begin{array}{l}\text { expectation of manager in administrative } \\
\text { division }\end{array}$ & Cost \\
\hline $\begin{array}{l}\text { Use of hydraulic energy than the electrical } \\
\text { one }\end{array}$ & expectation of assembly line & Benefit \\
\hline Commitment of personnel for GSCM & $\begin{array}{l}\text { expectation of manager in administrative } \\
\text { division }\end{array}$ & Benefit \\
\hline $\begin{array}{l}\text { Environmentally friendly packaging of } \\
\text { purchased components }\end{array}$ & expectation of inventory control division & Benefit \\
\hline Reusability of brackets, clinches and frames & $\begin{array}{l}\text { expectations of bracket clinching and frame } \\
\text { and bracket engraving divisions }\end{array}$ & Benefit \\
\hline Use of waste of other companies & $\begin{array}{l}\text { expectation of manger in administrative } \\
\text { division }\end{array}$ & Benefit \\
\hline Sale of scrap materials & expectation of inventory control division & Benefit \\
\hline Weldability of scrap frame's sub-components & expectation of welding division & Benefit \\
\hline
\end{tabular}

A survey was directed through the distribution of a questionnaire between three experts of a motorcycle manufacturing company. Three decision makers were selected including an operations manager (DM1), a purchasing manager (DM2), and an environmental manager (DM3). These experts were selected from the company of Zanjan Matin Khodro. The respondents were asked to assign a score to each criterion to determine its importance and also to rank performance of company in three different specifications of green purchasing, green warehousing and green recycling independently. A seven-point Likert scale was used in the questionnaire to provide experts' opinions. The linguistic variable for rating ranged from 1 (very poor) to 7 (very good) and the importance weight of criteria varied from 1 (very low) to 7 (very high) are applied in Table 2 and 3 respectively. An excerpt of the questionnaire for evaluating environmental criteria is indicated in Table 4.

Table2. Linguistic variable for relative importance weight of criteria

\begin{tabular}{|lc|}
\hline Linguistic variable & Fuzzy numbers \\
\hline Very low (VL) & $(0,0,0.1)$ \\
Low (L) & $(0,0.1,0.3)$ \\
Medium low (ML) & $(0.1,0.3,0.5)$ \\
Medium (M) & $(0.3,0.5,0.7)$ \\
Medium high (MH) & $(0.5,0.7,0.9)$ \\
High (H) & $(0.7,0.9,1)$ \\
\hline Very high (VH) & $(0.9,1,1)$ \\
\hline
\end{tabular}

Table3. Linguistic variable for rating

\begin{tabular}{|lc|}
\hline \multicolumn{1}{|c|}{ Linguistic variable } & Fuzzy numbers \\
\hline Very poor (VP) & $(0,0,1)$ \\
Poor (P) & $(0,1,3)$ \\
Medium poor (MP) & $(1,3,5)$ \\
Medium (M) & $(3,5,7)$ \\
Medium good (MG) & $(5,7,9)$ \\
Good (G) & $(7,9,10)$ \\
\hline Very good (VG) & $(9,10,10)$ \\
\hline
\end{tabular}


Table4. An excerpt of the questionnaire for evaluating environmental criteria

\begin{tabular}{|l|l|l|l|l|l|l|l|}
\hline \multicolumn{1}{|c|}{ Criteria } & $\begin{array}{l}\text { Very } \\
\text { low }\end{array}$ & Low & $\begin{array}{l}\text { Medium } \\
\text { low }\end{array}$ & Medium & $\begin{array}{l}\text { Medium } \\
\text { high }\end{array}$ & High & $\begin{array}{l}\text { Very } \\
\text { high }\end{array}$ \\
\hline Presence of hazardous materials & & & & & & & \\
\hline $\begin{array}{l}\text { Use of environmentally friendly } \\
\text { technology }\end{array}$ & & & & & & & \\
\hline $\begin{array}{l}\text { Lack of environmentally friendly } \\
\text { materials }\end{array}$ & & & & & & & \\
\hline $\begin{array}{l}\text { Use of hydraulic energy than the } \\
\text { electrical one }\end{array}$ & & & & & & & \\
\hline Commitment of personnel for GSCM & & & & & & & \\
\hline $\begin{array}{l}\text { Environmentally friendly packaging of } \\
\text { purchased components }\end{array}$ & & & & & & \\
\hline $\begin{array}{l}\text { Reusability of brackets, clinches and } \\
\text { frames }\end{array}$ & & & & & & & \\
\hline Use of waste of other companies & & & & & & & \\
\hline Sale of scrap materials & & & & & & & \\
\hline $\begin{array}{l}\text { Weldability of scrap frame's sub- } \\
\text { components }\end{array}$ & & & & & & \\
\hline
\end{tabular}

Table 5 indicates the fuzzy weights information resulted of assessment provided by the three DMs. In addition, rates of each of criteria for green practices of Sepehr Khodro, which are given by DMs, are shown in Tables 6,7 and 8 .

Table5. Importance and aggregate fuzzy weights of the criteria from three decision makers

\begin{tabular}{|c|c|c|c|c|c|c|}
\hline Criteria & DM1 & DM2 & DM3 & Cost / benefit & $\mathrm{C}+/ \mathrm{A}-$ & Aggregate numbers \\
\hline $\mathrm{C} 1$ & VH $(0.9,1,1)$ & $\mathbf{H}(0.7,0.9,1)$ & $\mathbf{H}(0.7,0.9,1)$ & Cost & $(0.7,0.9,1)$ & $(0.76,0.93,1)$ \\
\hline $\mathrm{C} 2$ & H $(0.7,0.9,1)$ & VH $(0.9,1,1)$ & VH $(0.9,1,1)$ & Benefit & $(0.9,1,1)$ & $(0.83,0.96,1)$ \\
\hline $\mathrm{C} 3$ & MH $(0.5,0.7,0.9)$ & $\mathbf{H}(0.7,0.9,1)$ & $\mathbf{H}(0.7,0.9,1)$ & Cost & $(0.5,0.7,0.9)$ & $(0.63,0.83,0.96)$ \\
\hline $\mathrm{C} 4$ & $\mathbf{L}(0,0.1,0.3)$ & $\mathbf{M}(0.3,0.5,0.7)$ & $\mathbf{M}(0.3,0.5,0.7)$ & Benefit & $(0.3,0.5,0.7)$ & $(0.2,0.36,0.56)$ \\
\hline $\mathrm{C} 5$ & ML $(0.1,0.3,0.5)$ & ML $(0.1,0.3,0.5)$ & $\mathbf{M}(0.3,0.5,0.7)$ & Benefit & $(0.3,0.5,0.7)$ & $(0.16,0.36,0.56)$ \\
\hline C6 & $\mathbf{H}(0.7,0.9,1)$ & $\mathbf{H}(0.7,0.9,1)$ & $\mathbf{H}(0.7,0.9,1)$ & Benefit & $(0.7,0.9,1)$ & $(0.7,0.9,0.1)$ \\
\hline $\mathrm{C} 7$ & VH $(0.9,1,1)$ & МH $(0.5,0.7,0.9)$ & VH $(0.9,1,1)$ & Benefit & $(0.9,1,1)$ & $(0.76,0.9,0.96)$ \\
\hline $\mathrm{C} 8$ & ML $(0.1,0.3,0.5)$ & $\mathbf{L}(0,0.1,0.3)$ & ML $(0.1,0.3,0.5)$ & Benefit & $(0.1,0.3,0.5)$ & $(0.066,0.23,0.43)$ \\
\hline C9 & VH $(0.9,1,1)$ & VH $(0.9,1,1)$ & VH $(0.9,1,1)$ & Benefit & $(0.9,1,1)$ & $(0.9,1,1)$ \\
\hline $\mathrm{C} 10$ & $\mathbf{M}(0.3,0.5,0.7)$ & H $(0.7,0.9,1)$ & H $(0.7,0.9,1)$ & Benefit & $(0.7,0.9,1)$ & $(0.56,0.76,0.9)$ \\
\hline
\end{tabular}

Table6. Ratings of DMs for green purchasing performance of Sepehr Khodro company

\begin{tabular}{|c|c|c|c|c|c|}
\hline \multirow[t]{2}{*}{ Criteria } & \multicolumn{5}{|c|}{ Green purchasing } \\
\hline & DM1 & DM2 & DM3 & Aggregate & Cost or benefit criteria \\
\hline $\mathrm{C} 1$ & MP & MG & MP & $(1,4.33,9)$ & Cost \\
\hline $\mathrm{C} 2$ & $\mathrm{P}$ & VP & MP & $(0,1.33,3)$ & Benefit \\
\hline $\mathrm{C} 3$ & M & MG & MP & $(1,5,9)$ & Cost \\
\hline $\mathrm{C} 4$ & M & MP & MP & $(1,3.67,7)$ & Benefit \\
\hline $\mathrm{C} 5$ & MP & MP & M & $(1,3.67,7)$ & Benefit \\
\hline C6 & MG & MP & M & $(1,5,9)$ & Benefit \\
\hline $\mathrm{C} 7$ & M & $\mathrm{P}$ & MP & $(0,3,7)$ & Benefit \\
\hline $\mathrm{C} 8$ & MG & MG & MP & $(1,5.67,9)$ & Benefit \\
\hline C9 & MG & MG & M & $(3,6.33,9)$ & Benefit \\
\hline $\mathrm{C} 10$ & MP & VP & $\mathrm{P}$ & $(0,1.33,3)$ & Benefit \\
\hline
\end{tabular}


Table7. Ratings of DMs for green warehousing performance of Sepehr Khodro company

\begin{tabular}{|lllllc|}
\hline Criteria & \multicolumn{5}{c|}{ Green warehousing } \\
& DM1 & DM2 & DM3 & Aggregate & Cost or benefit criteria \\
C1 & G & MG & VG & $(5,8.67,10)$ & Cost \\
C2 & MG & MP & M & $(1,5,9)$ & Benefit \\
C3 & MG & G & VG & $(5,8.67,10)$ & Cost \\
C4 & G & VG & G & $(7,9.33,10)$ & Benefit \\
C5 & G & M & G & $(3,7.67,10)$ & Benefit \\
C6 & MG & MP & M & $(1,5,9)$ & Benefit \\
C7 & G & VG & G & $(7,9.33,10)$ & Benefit \\
C8 & MG & MG & G & $(5,7.67,10)$ & Benefit \\
C9 & G & MG & M & $(3,7,10)$ & Benefit \\
C10 & MG & G & MG & $(5,7.67,10)$ & Benefit \\
\hline
\end{tabular}

Table8. Ratings of DMs for green recycling performance of Sepehr Khodro company

\begin{tabular}{|lllllc|}
\hline Criteria & & & & Green recycling & \\
& DM1 & DM2 & DM3 & Aggregate & Cost or benefit criteria \\
C1 & MG & MP & MG & $(1,5.67,9)$ & Cost \\
C2 & G & M & G & $(3,7.67,10)$ & Benefit \\
C3 & G & MG & MG & $(5,6.67,10)$ & Cost \\
C4 & G & VG & G & $(7,9.33,10)$ & Benefit \\
C5 & G & M & G & $(3,7.67,10)$ & Benefit \\
C6 & MG & MP & M & $(1,5,9)$ & Benefit \\
C7 & MG & G & MG & $(5,7.67,10)$ & Benefit \\
C8 & MG & MG & G & $(5,7.67,10)$ & Benefit \\
C9 & G & VG & G & $(7,9.33,10)$ & Benefit \\
C10 & G & MG & VG & $(5,8.67,10)$ & Benefit \\
\hline
\end{tabular}

The normalized and weighted normalized fuzzy decision matrix, the distance of each practices (green purchasing, warehousing and recycling) from positive-ideal solution (PIS) and negative-ideal solution (NIS) with respect to each criterion and the closeness coefficient (CCi) of each practices are indicated, respectively, in Tables 9-15. All the calculations were performed by using MS Excel. The results of fuzzy TOPSIS analysis are summarized in Table 15. The closeness coefficients are sorted from G1 (green purchasing) to G2 (green warehousing) and G3 (green recycling) respectively. Based on the $\mathrm{CCi}$ values, the ranking order of the three practices is: $\mathrm{G} 3>\mathrm{G} 1>\mathrm{G} 2$.

Table9. Normalized fuzzy-decision matrix

\begin{tabular}{|cccc|}
\hline Criteria & & & \\
& G1 & G2 & G3 \\
C1 & $(0.7,0.9,1.1)$ & $(0.7,1,1)$ & $(0.7,1,1.43)$ \\
C2 & $(0.7,0.9,1.1)$ & $(0.9,1,1.1)$ & $(0.9,1,1.1)$ \\
C3 & $(0.55,1,1.8)$ & $(0.5,0.77,1.28)$ & $(0.5,0.77,1.28)$ \\
C4 & $(0,0.2,1)$ & $(0.43,1,2.3)$ & $(0.43,1,2.3)$ \\
C5 & $(0.14,0.6,1.6)$ & $(0.14,0.6,1.6)$ & $(0.43,1,2.3)$ \\
C6 & $(0.7,1,1.43)$ & $(0.7,1,1.43)$ & $(0.7,1,1.43)$ \\
C7 & $(0.9,1,1.1)$ & $(0.5,0.7,1)$ & $(0.9,1,1.1)$ \\
C8 & $(0.2,1,5)$ & $(0,0.33,3)$ & $(0.2,1,5)$ \\
C9 & $(0.9,1,1.1)$ & $(0.9,1,1.1)$ & $(0.9,1,1.1)$ \\
C10 & $(0.3,0.55,1)$ & $(0.7,1,1.43)$ & $(0.7,1,1.43)$ \\
\hline
\end{tabular}


Table10. Weighted normalized fuzzy-decision matrix

\section{Criteria}

\begin{tabular}{|cccc|}
\hline Criteria & G1 & G2 & G3 \\
\hline C1 & $(0.53,0.83,1.1)$ & $(0.53,0.93,1)$ & $(0.53,0.93,1.43)$ \\
C2 & $(0.58,0.86,1.1)$ & $(0.74,0.96,1.1)$ & $(0.74,0.96,1.1)$ \\
C3 & $(0.34,0.83,1.72)$ & $(0.31,0.63,1.22)$ & $(0.31,0.63,1.22)$ \\
C4 & $(0.0,0.07,0.56)$ & $(0.08,0.36,1.28)$ & $(0.08,0.36,1.28)$ \\
C5 & $(0.02,0.21,0.89)$ & $(0.02,0.21,0.89)$ & $(0.06,0.36,1.28)$ \\
C6 & $(0.49,0.9,0.14)$ & $(0.49,0.9,0.14)$ & $(0.49,0.9,0.14)$ \\
C7 & $(0.68,0.9,1.05)$ & $(0.38,0.63,0.96)$ & $(0.68,0.9,1.05)$ \\
C8 & $(0.01,0.23,2.15)$ & $(0,0.07,1.29)$ & $(0.01,0.23,2.15)$ \\
C9 & $(0.81,1,1.1)$ & $(0.81,1,1.1)$ & $(0.81,1,1.1)$ \\
C10 & $(0.16,0.41,0.9)$ & $(0.39,0.76,1.2)$ & $(0.39,0.76,1.2)$ \\
\hline
\end{tabular}

Table11. Ideal solutions based on formula number 11

\begin{tabular}{|lcccccccccc|}
\hline & C1 & C2 & C3 & C4 & C5 & C6 & C7 & C8 & C9 & C10 \\
G1 & 0.84 & 0.83 & 0.98 & 0.21 & 0.44 & 0.5 & 0.87 & 0.79 & 0.97 & 0.48 \\
G2 & 0.82 & 0.93 & 0.71 & 0.58 & 0.44 & 0.5 & 0.65 & 0.45 & 0.97 & 0.78 \\
G3 & 0.51 & 0.93 & 0.71 & 0.58 & 0.56 & 0.5 & 0.87 & 0.79 & 0.97 & 0.78 \\
\hline
\end{tabular}

Table 12. Positive and negative ideal solutions

\begin{tabular}{|ccccccccccc|}
\hline & C1 & C2 & C3 & C4 & C5 & C6 & C7 & C8 & C9 & C10 \\
G* & $(0.53,0.8$ & $(0.74,0.9$ & $(0.34,0.8$ & $(0.08,0.3$ & $(0.06,0.3$ & $(0.49,0.9$ & $(0.68,0.9$ & $(0.01,0.2$ & $(0.81,1,1$ & $(0.39,0.7$ \\
& $3,1.1)$ & $6,1.1)$ & $3,1.72)$ & $6,1.28)$ & $6,1.28)$ & $, 0.14)$ & $, 1.05)$ & $3,2.15)$ & $.1)$ & $6,1.2)$ \\
G- & $(0.53,0.9$ & $(0.58,0.8$ & $(0.31,0.6$ & $(0.08,0.3$ & $(0.02,0.2$ & $(0.49,0.9$ & $(0.38,0.6$ & $(0,0.07,1$ & $(0.81,1,1$ & $(0.16,0.4$ \\
& $3,1.43)$ & $6,1.1)$ & $3,1.22)$ & $6,1.28)$ & $1,0.89)$ & $, 0.14)$ & $3,0.96)$ & $.29)$ & $.1)$ & $1,0.9)$ \\
\hline
\end{tabular}

Table13. Distances between Green practices and $\mathrm{G}^{*}$ (positive ideal solution) with respect to each criterion

\begin{tabular}{|lcccccccccc|}
\hline & $\mathrm{C} 1$ & $\mathrm{C} 2$ & $\mathrm{C} 3$ & $\mathrm{C} 4$ & $\mathrm{C} 5$ & $\mathrm{C} 6$ & $\mathrm{C} 7$ & $\mathrm{C} 8$ & $\mathrm{C} 9$ & $\mathrm{C} 10$ \\
$\begin{array}{l}\text { The distance of Green purchasing and } \\
\text { ideal solution } \mathrm{d}\left(\mathrm{G} 1, \mathrm{G}^{*}\right)\end{array}$ & 0.0 & 0.12 & 0.0 & 0.44 & 0.25 & 0.0 & 0.0 & 0.0 & 0.0 & 0.28 \\
$\begin{array}{l}\text { The distance of Green warehousing and } \\
\text { ideal solution } \mathrm{d}\left(\mathrm{G} 2, \mathrm{G}^{*}\right)\end{array}$ & 0.081 & 0.0 & 0.31 & 0.0 & 0.25 & 0.0 & 0.25 & 1.21 & 0.0 & 0.0 \\
$\begin{array}{l}\text { The distance of Green recycling and ideal } \\
\text { solution } \mathrm{d}\left(\mathrm{G} 3, \mathrm{G}^{*}\right)\end{array}$ & 0.19 & 0.0 & 0.31 & 0.0 & 0.0 & 0.0 & 0.0 & 0.0 & 0.0 & 0.0 \\
\hline
\end{tabular}

Table14. Distances between Green practices and G- (negative ideal solution) with respect to each criterion

\begin{tabular}{|lcccccccccc|}
\hline & C1 & C2 & C3 & C4 & C5 & C6 & C7 & C8 & C9 & C10 \\
$\begin{array}{l}\text { The distance of Green purchasing and } \\
\text { negative solution d(G1, G-) }\end{array}$ & 0.19 & 0.0 & 0.31 & 0.0 & 0.0 & 0.0 & 0.25 & 1.21 & 0.0 & 0.0 \\
$\begin{array}{l}\text { The distance of Green warehousing and } \\
\text { negative solution d(G2, G-) }\end{array}$ & 0.24 & 0.12 & 0.0 & 0.44 & 0.0 & 0.0 & 0.0 & 0.0 & 0.0 & 0.28 \\
$\begin{array}{l}\text { The distance of Green recycling and } \\
\text { negative solution d(G3, G-) }\end{array}$ & 0.0 & 0.12 & 0.0 & 0.44 & 0.25 & 0.0 & 0.25 & 1.21 & 0.0 & 0.28 \\
\hline
\end{tabular}

Table15. Computations of $\mathrm{d}+, \mathrm{d}-$ and $\mathrm{CCi}$

\begin{tabular}{|ccccc|}
\hline & $\mathrm{d}+$ & $\mathrm{d}-$ & $\mathrm{CCi}$ & Ranking \\
$\mathrm{G} 1$ & 1.09 & 1.96 & 0.64 & 2 \\
$\mathrm{G} 2$ & 2.1 & 1.08 & 0.33 & 3 \\
$\mathrm{G} 3$ & 0.5 & 2.55 & 0.83 & 1 \\
\hline
\end{tabular}




\section{Conclusion and future direction}

The objective of the current study was to provide an comprehensive process to find and rank the most important practices of green supply chain management (GSCM) for an practical case study of Zanjan Sepehr Khodro. Firstly, a systematic literature review was conducted to find the major practices of green supply chain management (GSCM). Next, three practices were selected with their sub-criteria according to their frequency of application. These practices (green purchasing, green warehousing and green recycling) were then categorized based on the major perspectives of green supply chain management (GSCM). Afterward, A Fuzzy TOPSIS was applied to rank the green supply chain management (GSCM) practices and find their significance in associated company. According to the results, green recycling, green purchasing and green warehousing are ranked based on their significance respectively. The results lead motorcycle companies including both manufacturing and assembly to take better policies for their own management. These results help managers to prioritize their orders, as the importance of recycling is determined comparing purchasing and warehousing. Finally, the study proposes to the future researchers to invest on numbers of fuzzy numbers by developing these numbers, which will help to a better analysis of complicated problems with higher practices.

\section{References}

[1] Azzone G, Noci G. Measuring the environmental performance of new products: an integrated approach. International Journal of Production Research 1996;34(11):3055-78.

[2] Bai C, Sarkis J. Integrating sustainability into supplier selection with grey system and rough set methodologies. International Journal of Production Economics 2010;124(1):252-64.

[3] Bellman RE, Zadeh LA. Decision making in a fuzzy environment. Journal of Management Science 1970;17(4):141-64.

[4] Boiral O. Global warming: should companies adopt a proactive strategy? Long Range Planning 2006;39:315-30.

[5] Buyukozkan G, Cifci G. A novel fuzzy multi-criteria decision framework for sustainable supplier selection with incomplete information. Computers in Industry 2011;62:164-74.

[6] Buyukozkan G, Cifci G. A novel hybrid MCDM approach based on fuzzy DEMATEL, fuzzy ANP and fuzzy TOPSIS to evaluate green suppliers. Expert Systems with Applications 2012;39:3000-11.

[7] Chen CT. Extensions of the TOPSIS for group decision-making under fuzzy environment. Fuzzy Sets System 2000;114:1-9.

[8] Chen CC. Incorporating green purchasing into the frame of ISO 14000. Journal of Cleaner Production 2005;13:927-33.

[9] Chen CT, Lin CT, Huang SF. A fuzzy approach for supplier evaluation and selection in supply chain management. International Journal of Production Economics 2006;102:289-301.

[10] Dalalah D, Hayajneh M, Batieha F. A fuzzy multi-criteria decision making model for supplier selection. Expert Systems with Applications 2011;38:8384-91.

[11] Diabat A, Govindan K. An analysis of the drivers affecting the implementation of green supply chain management. Resources, Conservation and Recycling 2011;55(6):659-67.

[12] Eltayeb TK, Zailani S, Ramayah T. Green supply chain initiatives among certified companies in Malaysia and environmental sustainability: investigating the outcomes. Resources, Conservation and Recycling 2011;55:495-506.

[13] Enarsson L. Evaluation of suppliers: how to consider the environment. International Journal of Physical Distribution and Logistics Management 1998;28(1):5-17.

[14] Fu X, Zhu Q, Sarkis J. Evaluating green supplier development programs at a telecommunications systems provider. International Journal of Production Economics 2012;140(1):357-67.

[15] Gonzalez P, Sarkis J, Adenso-Diaz B. Environmental management system certification and its influence on corporate practices Evidence from the automotive industry. International Journal of Operations and Production Management 2008;28(11):1021-41.

[16] Govindan K, Khodaverdi R, Jafarian A. A fuzzy multi criteria approach for measuring sustainability performance of a supplier based on triple bottom line approach, Journal of Cleaner Production, http://dx.doi.org/10.1016/j.jclepro.2012.04.014, in press.

[17] Handfield R, Walton SV, Sroufe R, Melnyk SA. Applying environmental criteria to supplier assessment: a study in the application of the analytical hierarchy process. European Journal of Operational Research 2002;141:70-87.

[18] Hsu CW, Hu AH. Applying hazardous substance management to supplier selection using analytic network process. Journal of Cleaner Production 2009;17(2):255-64.

[19] Hsu CW, Kuo TC, Chen SH, Hu AH. Using DEMATEL to develop a carbon management model of supplier selection in green supply chain management. Journal of Cleaner Production; in press.

[20] Huang SH, Keskar H. Comprehensive and configurable practices for supplier selection. International Journal of Production Economics 2007;105:510-23.

[21] Humphreys PK, Wong YK, Chan FTS. Integrating environmental criteria into the supplier selection process. Journal of Materials Processing Technology 2003a; 138:34956.

[22] Humphreys P, McIvor R, Chan F. Using case-based reasoning to evaluate supplier environmental management performance. Expert Systems with Applications 2003b;25:141-53.

[23] Humphreys P, McCloskey A, McIvor R, Maguire L, Glackin C. Employing dynamic fuzzy membership functions to assess environmental performance in the supplier selection process. International Journal of Production Research 2006;44(12):2379-419.

[24] Hwang CL, Yoon K. Multiple Attribute Decision Making. Berlin: Springer-Verlag; 1981.

[25] Jabbour LS, Jabbour CJC. Are supplier selection criteria going green? Case studies of companies in Brazil. Industrial Management \& Data Systems 2009;109(4):477-95.

[26] Kannan G, Pokharel S, Kumar PS. A hybrid approach using ISM and fuzzy TOPSIS for the selection of reverse logistics provider. Resources, Conservation and Recycling 2009;54(1):28-36.

[27] Kuo RJ, Wang YC, Tien FC. Integration of artificial neural network and MADA methods for green supplier selection. Journal of Cleaner Production 2010;18: 1161-70.

[28] Lee AHI, Kang HY, Hsu CF, Hung HC. A green supplier selection model for high-tech industry. Expert Systems with Applications 2009;36:7917-27.

[29] Lin RJ. Using fuzzy DEMATEL to evaluate the green supply chain management practices. Journal of Cleaner Production; in press.

[30] Lu LY, Wu CH, Kuo TC. Environmental principles applicable to green supplier evaluation by using multi-objective decision analysis. International Journal of Production Research 2007;45(18-19):4317-31.

[31] Lun YHV. Green management practices and firm performance: a case of container terminal operations. Resources, Conservation and Recycling 2011;55(6):559-66. 
[32] Noci G. Supporting decision making on recycling based investment. Business Strategy and the Environment 1995;4(2):62-72.

[33] Noci G. Designing green vendor rating systems for the assessment of a supplier's environmental performance. European Journal of Purchasing and Supply Management 1997;3(2):103-14.

[34] Olugu EU, Wong KY, Shaharoun AM. Development of key performance measures for the automobile green supply chain. Resources, Conservation and Recycling 2011;55(6):567-79.

[35] Onut S, Kara SS, Isik E. Long term supplier selection using a combined fuzzy MCDM approach: a case study for a telecommunication company. Expert Systems with Applications 2009;36:3887-95.

[36] Sarkis J. Evaluating environmentally conscious business practices. European Journal of Operational Research 1998;107:159-74.

[37] Sarkis J. Manufacturer's role in corporate environmental sustainability-concerns for the new millennium. International Journal of Operations and Production Management 2001;21(5-6):666-86.

[38] Sarkis J. Greening the Supply Chain. Berlin: Springer; 2006.

[39] Shanian A, Savadogo O. TOPSIS multiple-criteria decision support analysis for material selection of metallic bipolar plates for polymer electrolyte fuel cell. Journal of Power Sources 2006;159:1095-104.

[40] Shaw K, Shankar R, Yadav SS, Thakur LS. Supplier selection using fuzzy AHP and fuzzy multi-objective linear programming for developing low carbon supply chain. Expert Systems with Applications 2012;39(9):8182-92.

[41] Shih HSh, Shyur HJ, Lee ES. An extension of TOPSIS for group decision making. Journal of Mathematical and Computer Modeling 2007;45:801-13.

[42] Srivastava SK. Green supply-chain management: a state-of-the-art literature review. International Journal of Management Reviews 2007;9(1):53-80.

[43] Tseng ML. Using linguistic preferences and grey relational analysis to evaluate the environmental knowledge management capacities. Expert Systems with Applications 2010;37(1):70-81.

[44] Tseng ML, Chiu ASF. Evaluating firm's green supply chain management in linguistic preferences. Journal of Cleaner Production; in press.

[45] Tseng ML, Wang R, Chiu ASF, Geng Y, Lin YH. Improving performance of green innovation practices under uncertainty. Journal of Cleaner Production; in press.

[46] Tuzkaya G, Ozgen A, Ozgen D, Tuzkaya UR. Environmental performance evaluation of suppliers: a hybrid fuzzy multi-criteria decision approach. International Journal of Environmental Science and Technology 2009;6(3):477-90.

[47] Walker H, Sisto LD, McBain D. Drivers and barriers to environmental supply chain management practices: lessons from the public and private sectors. Journal of Purchasing and Supply Management 2008;14:69-85.

[48] Walton SV, Handfield RB, Melnyk SA. The green supply chain: integrating suppliers into environmental management processes. International Journal of Purchasing and Materials Management 1998;34(2):2-11.

[49] Wang TC, Chang TH. Application of TOPSIS in evaluating initial training aircraft under a fuzzy environment. Expert Systems with Applications 2007;33:870-80.

[50] Wang YM, Elhag TMS. Fuzzy TOPSIS method based on alpha level sets with an application to bridge risk assessment. Expert Systems with Applications 2006;31:309-19.

[51] Wang YJ, Lee HS. Generalizing TOPSIS for fuzzy multiple-criteria group decision-making. Journal of Computers and Mathematics with Applications 2007;53:1762-72.

[52] Wang JW, Cheng C, Cheng HK. Fuzzy hierarchical TOPSIS for supplier selection. Journal of Applied Soft Computing 2009;9:37786.

[53] Yeh WC, Chuang MC. Using multi objective genetic algorithm for partner selection in green supply chain problems. Expert Systems with Applications 2011;38:4244-53.

[54] Yucel A, Guneri AF. A weighted additive fuzzy programming approach for multicriteria supplier selection. Expert Systems with Applications 2011;38:6281-6.

[55] Zadeh LA. Fuzzy sets. Information and Control 1965;8:338-53.

[56] Zadeh LA. A fuzzy algorithmic approach to the definition of complex or imprecise concepts. International Journal of Man-Machine Studies 1976;8:249-91.

[57] Zeydan M, Colpan C, Cobanoglu C. A combined methodology for supplier selection and performance evaluation. Expert Systems with Applications 2011;38:2741-51.

[58] Zhang HC. Foreword special section on the IEEE international symposium on electronics and the environment. IEEE Transactions on Electronics Packaging Manufacturing 2004;27(1):1.

[59] Zhu Q, Geng Y. Integrating environmental issues into supplier selection management. Greener Management International 2001;35:2740.

[60] Zhang HC, Li J. Using Fuzzy Multi-Agent Decision-Making in Environmentally Conscious Supplier Management. Annals of CIRP: Manufacturing Technology 2003;52/1:385-8.

[61] Zhu Q, Sarkis J, Geng Y. Green supply chain management in China: pressures, practices and performance. International Journal of Operations and Production Management 2007a;25(5):449-68.

[62] Zhu Q, Sarkis J, Lai KH. Green supply chain management: pressures, practices and performance within the Chinese automobile industry. Journal of Cleaner Production 2007b;15:1041-52.

[63] Zhu Q, Sarkis J, Lai K. An institutional theoretic investigation on the links between internationalization of Chinese manufacturers and their environmental supply chain management. Resources, Conservation and Recycling 2011;55(6):623-30.

[64] Zimmermann HJ. Fuzzy set theory and its applications. 4th ed. Boston: Kluwe Academic Publishers; 2001.

[65] Zouggari A, Benyoucef L. Simulation based fuzzy TOPSIS approach for group multi-criteria supplier selection problem. Engineering Application of Artificial Intelligence 2012;25(3):507-19. 